\title{
Evaluation of chemotherapy with nanosomal paclitaxel and gene therapy expressing apoptosis-inducing proteins in the management of spontaneous canine mammary neoplasm
}

\author{
Divya $\mathrm{M}^{1}$, Maiti $\mathrm{SK}^{2}$, Sangeetha $\mathrm{P}^{1}$, Shivaraju $\mathrm{S}^{1}$, Kumar $\mathrm{N}^{2}$, Tiwari $\mathrm{AK}^{3}$, Hescheler $\mathrm{J}^{4}$
}

\begin{abstract}
Mammary gland tumours are the second most common neoplasm representing about $40-50 \%$ of all neoplasm after skin tumour, but the majority of these tumours occur in intact/ non spaying female dogs. Surgical excision of the benign tumour is the standard treatment of canine mammary tumours. Chemotherapy is the choice of treatment if the tumour is malignant or shows evidence of invasion into lymph or blood vessels, however, they showed different side effects and their success rate is varied. Taxanes are now the most promising anti-cancer drugs with little side effects. Gene therapy expressing apoptosis-inducing proteins have ability to kill cancer cells while sparing normal cells. The present study was conducted for exploring the oncolytic effect of viral gene therapy expressing apoptosis-inducing proteins construct (ns1 + vp3), nanosomal paclitaxel as chemotherapeutic agent and surgical therapy in the management of spontaneous canine mammary tumours. Chemotherapy (nanosomal paclitaxel) $(n=10)$, viral gene construct $(n s 1+v p 3)(n=10)$ and surgical therapy (n=10) were used in 30 female dogs of different breeds having different types of spontaneous mammary tumours. Chemotherapeutic drug and viral gene construct (ns $1+v p 3$ ) induced apoptosis in canine mammary neoplasms were studied using fluorescent activated cell sorting analysis. However, apoptotic percentage was significantly higher in chemotherapeutic group than viral gene construct therapy. No major side effects were observed in any groups. Matrix metalloproteinase-2 was found as an important prognostic tool in the management of canine mammary tumours. In conclusion, chemotherapy with nanosomal paclitaxel proved better than viral gene construct (ns1 +vp3) in the treatment of canine mammary neoplasm.
\end{abstract}

Key Words: Mammary tumour, Flow cytometry; Chemotherapy; Apoptosis; Gene therapy expressing apoptosis-inducing proteins; Canine parvovirus ns1 gene; Chicken Anemia vp3 gene

\section{Introduction}

Cancer is a leading cause of death in both humans and canines. Cancer has gained considerable relevance in animals recently owing to increased awareness among people towards animal suffering and pain. The diagnosis and management of neoplasm, therefore, presents a major challenge faced by a veterinarian. Different modern cancer management modalities like excisional surgery, chemotherapy, hormone therapy, and immunotherapy either alone or in combination results in improved quality of life for patients with neoplasms. However, it does not lead to complete cure. The quality of life of the animal should always be prioritized $^{[1]}$.

Mammary gland tumours are the second most common neoplasm representing approximately $40-50 \%$ of all neoplasm after skin tumour, but the majority of these tumours occur in intact female $\operatorname{dogs}[2,3,4]$. Sex hormones play a vital role in the occurrence of mammary gland tumours. The hormones such as estrogen and progesterone are risk factors for this; shown by the fact that ovariohysterectomy decreases the incidence of mammary tumours by avoiding the influence of these hormones. Early spaying significantly decreases the risk of mammary tumour development ${ }^{[5]}$.
Mammary neoplasm in female dogs originates from epithelial cells lining ducts or alveoli, from myoepithelial cells or from interstitial connective tissues ${ }^{[6]}$. They can be either malignant or benign. The most common types among these are tumours from the glandular tissues and include adenoma, carcinoma, and adenocarcinoma. Mammary gland tumours are diagnosed by palpation of the mass, cytology of the cells contained within the mass, and radiographs to search for possible metástasis.

Chemotherapy is a kind of treatment that uses drugs to attack cancer cells. The importance of chemotherapy has been emphasized and it was reported that survival could be prolonged after chemotherapy in cancer patients ${ }^{[7,8]}$. However, no chemotherapy can guarantee a complete eradication of tumour cells from the body and a prolonged lifespan. All these therapies also have side effects and limitations. The taxanes includes paclitaxel and docetaxel, are among the most successful anticancer agents recently reported. Their primary mechanism of action is inhibition of the mitotic progression through binding and stabilization of the microtubules, which leads to inhibition of mitotic spindle function ${ }^{[9]}$.

Although, current chemo-radiotherapies are known to cause tumour regression by inducing apoptosis, failure to achieve preferential 
killing of tumour cells while leaving normal cells intact limits their wide -spread use ${ }^{[10]}$. A number of viruses with an ability to kill cancer cells while sparing normal cells have been discovered. Such viruses are called as oncolytic viruses ${ }^{[11]}$.These include adeno, herpes simplex, rabies, polio, measles, vesicular stomatitis, hepatitis A, bovine entero, mumps etc. Newcastle disease virus (NDV) is one such virus with an inherent oncolytic property that can be harnessed for the treatment of various cancers ${ }^{[12,13]}$. The chicken anemia viral protein (VP) 3, also termed apoptin kills tumour cells while sparing normal cells. Upon expression in normal cells, apoptin is accumulated in the cytoplasm whereas in cancer cells, it is specifically targeted to the nucleus where it elicits its lethal effects ${ }^{[14]}$. Canine parvovirus-2 (CPV-2) is an extremely simple DNA virus that encodes one to two early products and limited number of late structural proteins. It lacks mechanisms for inducing S phase and replicates only in proliferating host cells. This feature confers additional selectivity for killing rapidly growing cancer cells. The apoptosis-inducing activity of parvovirus was mapped to the non-structural protein-1,-2 (ns1/ns2) of minute virus of mice (MVM) and ns1 of parvovirus B19 ${ }^{[15]}$. Unlike apoptin, ns1 does not rely solely on apoptosis for its oncolytic effect. Certain viral genes act as tumour destructive agent, and the viral capsid as a nano-sized nucleic acid delivery vehicle. The greatest advantage that the oncolytic virus offers over chemotherapeutic agent is its ability to be engineered by in vitro genetic manipulation in response to preclinical and clinical findings.

Tumuorigenesis involves the accretion of unprogrammed genetic and epigenetic changes, which lead to dysregulation of the normal control of cell population. Metastasis is an important function of invading tumours. Dissolution of extracellular matrix (ECM) is an essential step for cancer cell metastasis. The proteinase primarily involved in tumour cell metastasis is the matrix metalloproteinase (MMPs) ${ }^{[16]}$. The MMPs, also called as matrixins, are a family of structurally and functionally related, zinc dependent endoproteinases that are involved in the dissolution of the ECM. MMPs are expressed in most invasive carcinomas, act as a prognostic marker and high levels of expression indicate a poor prognosis ${ }^{[17,18]}$.

The present study was, therefore, designed to investigate the therapeutic efficacy of chemotherapeutic agent- nanosomal paclitaxel and oncolytic viral gene construct in the management of spontaneously occurred canine mammary neoplasm.

\section{Materials and Methods}

\section{Experimental design}

The present study was conducted in 30 clinical dogs of different breeds having variable sizes of spontaneous mammary neoplasms (Figure 1A, B). The age of the animal varied between 6 to 14 years. They were randomly allotted to three different treatment groups consisting 10 animals in each group (Table 1,2). Attempts were made to allot same size of neoplasm in respective groups. We tried to maintain uniformity in different parameters including age of animal, size of tumour, histopathological types and TNM staging. Owner's consent was taken into consideration before grouping and therapy of these animals. All the CMN (canine mammary neoplasm) affected animals were intact during presentation.

\section{Clinico-biochemical examination}

Animals affected with mammary neoplasms were subjected to routine clinico-physiological monitoring of rectal temperature $\left({ }^{\circ} \mathrm{C}\right)$, pulse (beats/min) and respiration (breaths/min) on the first day of treatment and then weekly intervals. 5-ml of venous blood was collected for the estimation of hemoglobin ( $\mathrm{Hb})$, total leukocyte count (TLC) and differential leukocyte count (DLC) as per standard methods. Serum samples were also analyzed for Alanine amino transferase (ALT), aspirate amino transferase (AST) and alkaline phosphatase (ALP)using standard commercial diagnostic kits (M/S Span Diagnostic).

\section{Radiological examination}

Plain thoracic radiography for the detection of pulmonary metastases before treatment of any tumour was performed in all clinical cases.

\section{Histopathological examination}

Fine needle aspiration cytology was done as quick means for the diagnosis of the mammary tumour. Tumour samples (biopsy/surgically excised) were also collected and fixed immediately in $10 \%$ neutral buffered formalin, processed routinely by paraffin embedding technique, sections of 4-5 micron thickness were cut and stained by haematoxylin and eosin stain for histopathological examination.

\section{Chemotherapy}

In group I, patients having spontaneous mammary neoplasms were treated with anti-cancer drug nanosomal paclitaxel at the dose rate of $150 \mathrm{mg}$ per $32 \mathrm{~kg}$ body wt intravenously on day 0,21 and 35 . Each vial was diluted with $20 \mathrm{ml}$ normal saline and was given intravenous slowly. Supportive treatment like chlopheneramine maleate at the dose rate of $0.5 \mathrm{mg} \mathrm{kg}^{-1}$ intramuscular and pantoprazole at the dose rate of $1-2 \mathrm{mg} \mathrm{kg}^{-1}$ intravenous were also given.

\section{Oncolytic viral gene therapy}

Oncolytic viral gene construct was designed to kill cancer cells. Two oncolytic viral genes i.e. ns1 gene of CPV (Canine Parvo Virus) and vp3 gene of CIAV (Chicken Anaemia Virus) were used to explore their oncolytic ability to kill cancer cells. A bicistronic gene construct designated as pvivo2.ns1.vp3 was used to assess the efficacy in canine mammary tumour oncolysis. This gene construct was purified by QIAGEN HISPEED maxi column (catalogue no.12662). The purified constructs were used for oncolytic viral gene construct therapy. In short, the procedures include revival of recombinant $\mathrm{pVivo}$ NS1.VP3/pVivo2.NS1.VP3; bulk production and purification of recombinant plasmids and quantitative estimation of recombinant plasmids. Animals of group II were treated with pVivo2.NS1.VP3 at the dose rate of $100 \mu \mathrm{g}$ per animal by intratumoral route on four occasions at weekly intervals.

\section{Surgical therapy}

In group III animals having very large neoplasms and also as per the owner's request, surgical therapy was performed. All the animals were pre-medicated with atropine sulphate at a dose of $0.04 \mathrm{mg} \mathrm{kg}^{-1}$ body weight subcutaneously. After $10 \mathrm{~min}$, general anesthesia was achieved with combination of xylazine hydrochloride at the dose rate of $1 \mathrm{mg} \mathrm{kg}^{-1}$ and ketamine hydrochloride at the dose rate of $5 \mathrm{mg} \mathrm{kg}^{-1}$ body weight given intramuscularly. The anesthetic stage was prolonged by intravenous administration of combination of ketamine hydrochloride at the dose rate of $5 \mathrm{mg} \mathrm{kg}^{-1}$ and diazepam at the dose rate of $1 \mathrm{mg} \mathrm{kg}^{-1}$ body weight, if required. If a single gland was affected, then only that gland was removed; if multiple glands on one side were affected, then the entire 5 glands on that side were removed; if multiple tumours on both side were affected, then both mammary chains were removed; if the lymph node (axillary/inguinal) was within the resection zone, then they were also removed; if a growth was detected in the number 2 glands on the left side- glands 1,2, and 3 and the axillary lymph node on that side was removed; if it was found in the number 4 gland on the right side, then glands 3, 4, 5 and the inguinal lymph node on that side was removed; if the groin region was difficult to suture, a skin flap from the flank was needed to reconstruct the area. 

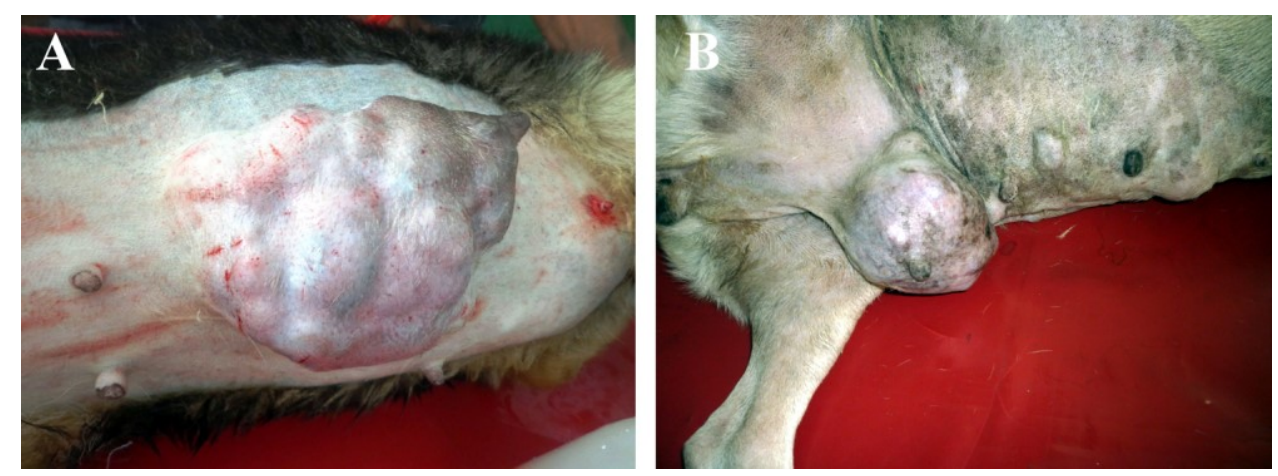

Figure 1 : Intact canine mammary tumours. A: Intact solitary growth involving right 3rd and 4th mammary gland in 10year old GSD bitch; B: Growth involving right 5th mammary gland in 12 yr old non-descript bitch

Table 1. Demographic data of all the patients

\begin{tabular}{|c|c|c|c|c|c|c|}
\hline Groups & $\begin{array}{c}\text { Animal } \\
\text { No. }\end{array}$ & Breed & Sex & Age (yrs) & $\begin{array}{c}\text { Body } \\
\text { weight } \\
(\mathrm{kg})\end{array}$ & Tumour types \\
\hline \multirow{10}{*}{ I } & $\mathrm{I}_{1}$ & Non-descript & Female & 12 & 10 & Papillary cystadenoma \\
\hline & $\mathrm{I}_{2}$ & Spitz & Female & 8 & 10 & Complex tubular carcinoma \\
\hline & $\mathrm{I}_{3}$ & Daschund & Female & 12 & 10 & Fibrosarcoma \\
\hline & $\mathrm{I}_{4}$ & Labrador & Female & 8 & 25 & Fibrosarcoma \\
\hline & $\mathrm{I}_{5}$ & GSD & Female & 10 & 42 & Mixed tumour \\
\hline & $\mathrm{I}_{6}$ & GSD & Female & 6 & 30 & Complex tubular carcinoma \\
\hline & $\mathrm{I}_{7}$ & Spitz & Female & 11 & 9 & Papillary cystadenoma \\
\hline & $\mathrm{I}_{8}$ & Spitz & Female & 10 & 11 & Osteochondroma \\
\hline & $\mathrm{I}_{9}$ & Non-descript & Female & 13 & 12 & Osteochondroma \\
\hline & $\mathrm{I}_{10}$ & Labrador & Female & 6 & 35 & Mixed papillary adenoma \\
\hline \multirow{10}{*}{ II } & $\mathrm{II}_{1}$ & Spitz & Female & 9 & 15 & Complex tubular carcinoma \\
\hline & $\mathrm{II}_{2}$ & Non-descript & Female & 12 & 15 & Mixed tumour \\
\hline & $\mathrm{II}_{3}$ & GSD & Female & 8 & 35 & Complex tubular carcinoma \\
\hline & $\mathrm{II}_{4}$ & Non-descript & Female & 9 & 18 & Complex tubular carcinoma \\
\hline & $\mathrm{II}_{5}$ & Spitz & Female & 14 & 10 & Fibrosarcoma \\
\hline & $\mathrm{II}_{6}$ & GSD & Female & 9 & 30 & Papillary adenocarcinoma \\
\hline & $\mathrm{II}_{7}$ & Labrador & Female & 11 & 38 & Lipid secreting carcinoma \\
\hline & $\mathrm{II}_{8}$ & Rottweiler & Female & 6 & 35 & Mixed malignant tumour \\
\hline & $\mathrm{II}_{9}$ & Non-descript & Female & 12 & 14 & Intraductal papillary adenocarcinoma \\
\hline & $\mathrm{II}_{10}$ & Spitz & Female & 8 & 10 & Fibrosarcoma \\
\hline \multirow{10}{*}{ III } & $\mathrm{III}_{1}$ & Spitz & Female & 15 & 8 & Complex tubular carcinoma \\
\hline & $\mathrm{III}_{2}$ & Spitz & Female & 12 & 10 & Complex tubular carcinoma \\
\hline & $\mathrm{III}_{3}$ & Spitz & Female & 12 & 8 & Fibrosarcoma \\
\hline & $\mathrm{III}_{4}$ & GSD & Female & 8 & 25 & Mixed malignant tumor \\
\hline & $\mathrm{III}_{5}$ & GSD & Female & 11 & 30 & Intraductal papillary adeno carcinoma \\
\hline & $\mathrm{III}_{6}$ & Spitz & Female & 12 & 6 & Papillary adenocarcinoma \\
\hline & $\mathrm{III}_{7}$ & Labrador & Female & 9 & 36 & Fibrosarcoma \\
\hline & $\mathrm{III}_{8}$ & Dachshund & Female & 11 & 10 & Mixed malignant tumour \\
\hline & $\mathrm{III}_{9}$ & Non-descript & Female & 12 & 10 & Lipid secreting carcinoma \\
\hline & $\mathrm{III}_{10}$ & Spitz & Female & 10 & 8 & Complex tubular carcinoma \\
\hline
\end{tabular}

Table 2. Summary of treatment protocol

\begin{tabular}{|c|c|c|c|}
\hline Groups & Type of therapy & Drug/Methods used & $\begin{array}{l}\text { No. of } \\
\text { animals }\end{array}$ \\
\hline II & $\begin{array}{c}\text { Oncolytic viral gene construct } \\
\text { therapy }\end{array}$ & $\begin{array}{c}\text { pVivo2.NS1.VP3 viral gene construct injected in tumour } \\
\text { mass locally on four occasions at weekly interval } \\
\text { @ } 100 \mu \mathrm{g} / \text { animal }\end{array}$ & 10 \\
\hline III & Surgical therapy & $\begin{array}{c}\text { Lumpectomy/simple mastectomy/en bloc dissection/half- } \\
\text { chain removal/unilateral mastectomy/radical } \\
\text { mastectomy. }\end{array}$ & 10 \\
\hline
\end{tabular}




\section{Postoperative care}

Broad spectrum antibiotics and analgesics with their standard dose rate were administered for five to seven postoperative days. Tumour recurrence was recorded for a minimum of one month to a maximum of one year of surgery. Drug tolerance of the patient was ascertained in all animals by recording the various side effects, if any, reported by the pet owners. Supportive therapy was instituted to alleviate such side effects.

\section{Apoptosis studies}

For apoptosis studies, biopsy samples of neoplasm were taken before the treatment and 1,2 and 3 weeks after treatment. They were subjected for the flow cytometric analysis of apoptosis using FACS caliber (Becton Dickinson, San Jose, CA). The samples were processed to prepare single cell suspension and then this suspension was subjected for FACS (Fluorescence Activated Cell Sorter) analysis to study the involvement of apoptosis in neoplasm regression. In this study, annexin V: FITC (catalogue number 556547 , BD biosciences) was used for staining the apoptotic cells

\section{Estimation matrix metalloproteinase (MMP)}

Blood samples were collected from all the animals of three groups at various time intervals and serum was separated and MMP (matrix metalloproteinase)-2 was estimated using MMP-2 ELISA kit (Blue gene, Shanghai, China).

\section{Statistical analysis}

The data pertaining to various parameters studied in canine cancer patients were analyzed using the "paired-t" test and analysis of variance (ANOVA) as per standard statistical methods. Statistical analysis was performed using SPSS software. $\mathrm{P}<0.05$ was considered significant except within group where $\mathrm{P}<0.01$ was considered highly significant.

\section{Ethical permission}

Necessary permission was undertaken from the Institute Animal Ethics Committee (IAEC) to conduct this research work in clinical cases.

\section{Results}

\section{Clinical assessment}

Canine mammary neoplasm cases were presented as circumscribed nodules with variable size, consistency and mobility to the skin and muscle. Grossly, the mammary gland tumours were soft to firm in consistency, tan to off-white in colour, pedunculated, sessile or subcutaneous masses that ranged from $5-9 \mathrm{~cm}$ at their largest dimension. They were sometimes also associated with skin ulceration and local inflammatory reactions. Multiple neoplasms were observed either in a single mammary gland or may involve multiple mammary glands, simultaneously. The age of the affected animals ranged from 6-14 years. Maximum cases were recorded in Spitz followed by German shepherd, non-descript, Daschund and Labrador. Most of the mammary gland neoplasm were observed in the $4^{\text {th }}$ (caudal abdominal) and $5^{\text {th }}$ (inguinal) mammary glands.

\section{Radiographic assessment}

Lateral radiography of the thorax of mammary tumour affected animals revealed no lung metastasis except in one case where radioopaque soft tissue scattered lesion in the lung parenchyma was observed (Figure 2).

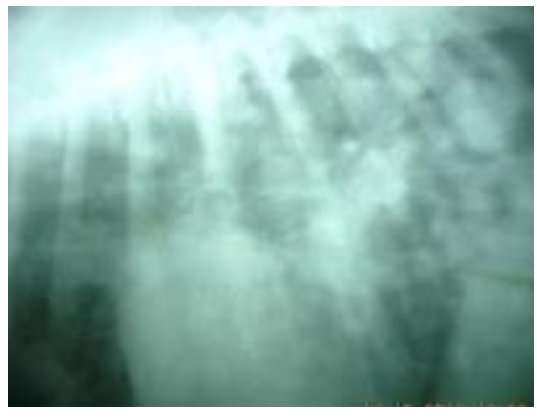

Figure 2: Lateral thoracic radiograph in a mammary tumour affected dog showing lung metastasis

\section{Histopathological assessment}

Fine needle aspiration biopsy revealed more number of mitotic figures in malignant cases. Most cytological sections revealed pleomorphism in nucleus, anisocytosis, and increase in particular cell population (Figure 3). Histopathologically, 16.67\% neoplasms were benign and $83.3 \%$ were malignant. The benign tumours were simple adenoma, mixed papillary adenoma (Figure 4A), osteochondroma (Figure 4B) and papillary cystadenoma. The malignant tumours were complex tubular carcinoma, lipid secreting carcinoma (Figure 4C), intraductal papillary adenocarcinoma (Figure 4D), fibrosarcoma and squamous cell carcinoma.

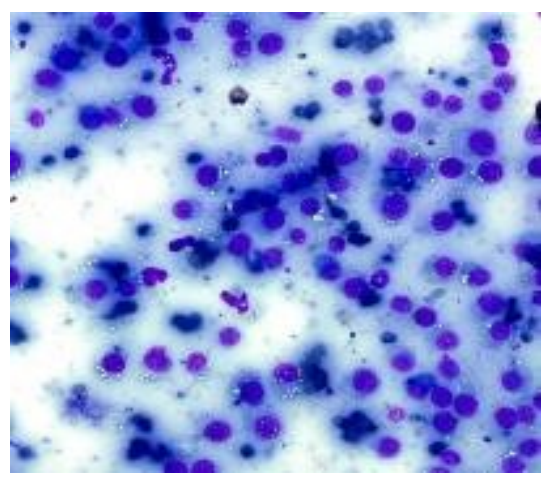

Figure 3: Fine needle aspiration cytology of canine mammary tumour. Showing anisocytosis and nuclear pleomorphism, Giemsa, $40 \mathrm{X}$.
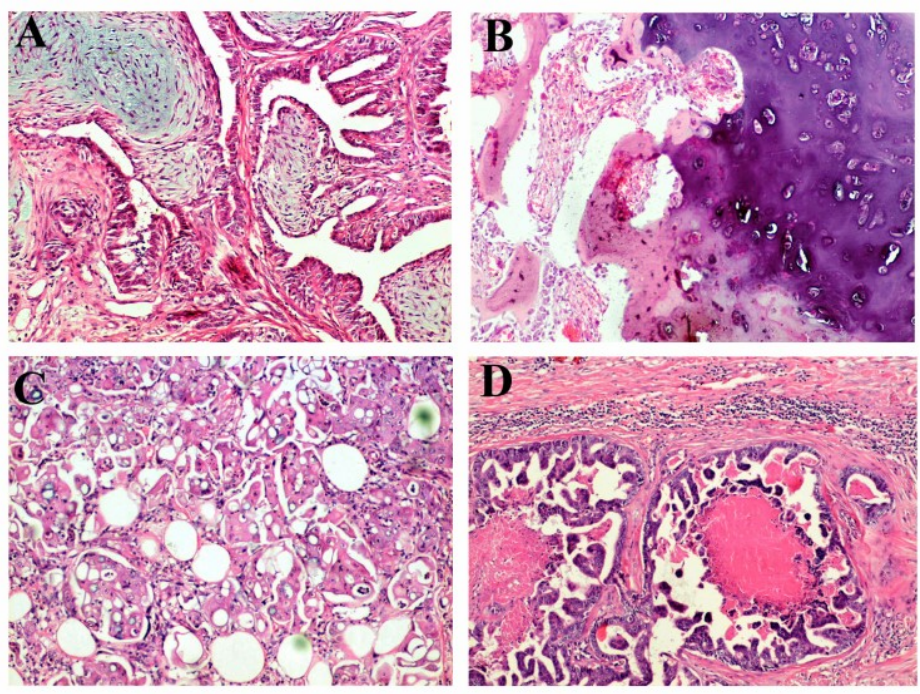

Figure 4: Histopathological section of mammary gland. A: Mixed papillary adenoma (H\&E, 10X); B:Osteochondroma (H\&E, 10X); C: Lipid secreting carcinoma (H\&E, 10X); D: Intraductal papillary adenocarcinoma (H\&E, 10X) 


\section{Therapeutic assessment}

In group I, animals were treated with nanosomal Paclitaxel at the dose rate of $150 \mathrm{mg}$ per $32 \mathrm{~kg}$ on 0,21 and 35 day along with supportive therapy depending on the response of the patient. Animals of this group showed a few symptoms including loss of apetite \& vomiting for first 2-3 days but that was not that severe. Untoward effects of the drug were controlled with supportive therapy. No severe side effects were observed in this group. Out of 10 cases, 8 cases showed regression of tumour (Figure 5A, B) whereas, one case could not be followed and other one subjected to surgery as per owner's request.

In group II, animals were treated with oncolytic viral gene construct at the dose rate of $100 \mu \mathrm{g}$ in $0.5 \mathrm{ml}$ volume intratumoural. Therapy was repeated thrice, once weekly. In two cases, there was infection at the site of injection, which was treated by antibiotic ointments successfully. There was subsequent decrease in size of tumour in 6 cases after oncolytic viral gene therapy (Figure 5C, D). Two cases could not be followed up because the case was not reported to the clinic, while in another two cases, the owner sought for surgical excision in spite of partial regression of mammary tumour.

All the tumour cases operated surgically in group III (Figure 5E, F) showed uneventful recovery with no postoperative complications except in two cases, where swelling and wound dehiscence was observed at the surgical site on $4^{\text {th }}$ and $6^{\text {th }}$ postoperative days. Sutures were removed on $11^{\text {th }}$ day. Complete wound healing was observed in these animals on $18^{\text {th }}$ postoperative day. Tumour recurrence was not observed in any of the surgically treated animals till one year of therapy.
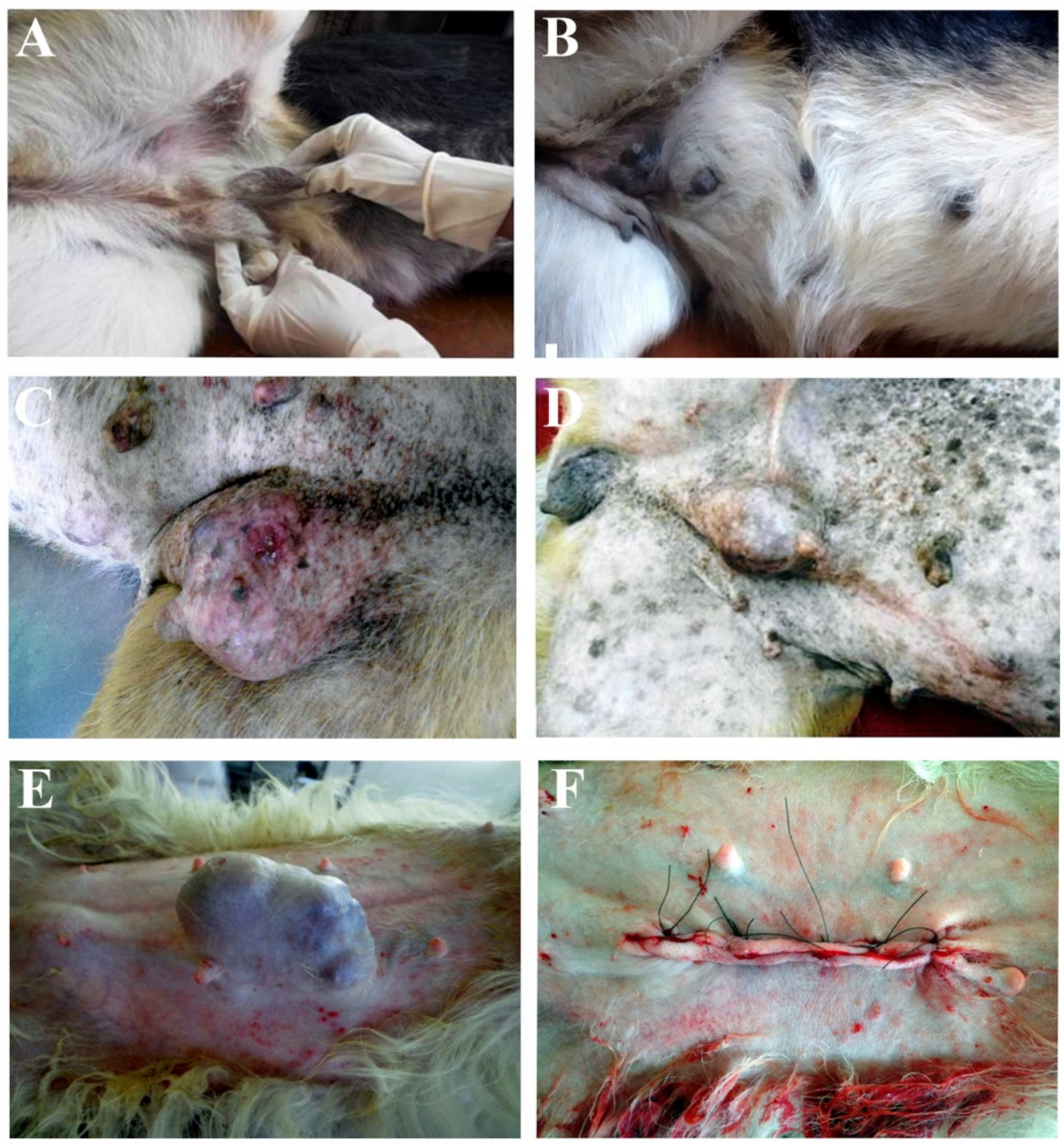

Figure 5: Canine mammary tumour therapy: A: Before chemotherapy; B: After chemotherapy; C: Before oncolytic gene construct therapy; D: After oncolytic gene construct therapy; E: Before surgical therapy; F: After surgical therapy 


\section{Clinico-physiological assessment}

Rectal temperature of the affected animals of three groups showed a non significant difference before, after and between treatments. Rectal temperature of all the animals of three groups remained within the normal range $\left(37.5-39.2^{\circ} \mathrm{C}\right)$. The pulse rate in all animals of three groups remained within the normal range (70-120 beats $\left.\min ^{-1}\right)$ throughout the treatment period with non significant variation from the base line value. The pulse rate recorded at different intervals did not show any significant difference between treatment groups of animals and also within group. Respiration rate of the affected animals of three groups showed a non significant difference before, after and between treatments. Respiration rate of all the animals in the three groups remained within the normal range (18-30 breaths $\left.\mathrm{min}^{-1}\right)$.

\section{Clinical staging of canine mammary neoplasm}

Clinical staging (TNM) of the mammary tumour was done as per WHO classifications. Out of 30 cases recorded, 16 cases in clinical stage I $(53.3 \%)$, followed by 5 cases in clinical stage III $(16.67 \%), 7$ cases were in clinical stage IV $(23.3 \%), 2$ case in clinical stage V $(6.67 \%)$ and none of the cases were seen in stage II.

\section{Hematological assessment}

Hemoglobin $(\mathrm{Hb})$ : In group $\mathrm{I}$, the $\mathrm{Hb}$ value significantly $(\mathrm{P}<0.05)$ reduced till the 3 rd week and thereafter increased from the $4^{\text {th }}$ week onwards. In group II, there was non significant variation of $\mathrm{Hb}$ during the course of therapy. In group III, Hb values apparently increased after the surgery compared to the values before surgery. However, in all groups, the $\mathrm{Hb}$ values remained within the normal limit $(8-16 \mathrm{~g} / \mathrm{dl})$. Total Leukocyte count (TLC): Total leukocyte count in the animals of group I, II and III did not show significant variation during the course of therapy and the values remained within the normal range (9-13 $\mathrm{x} 10^{3} /$ cubic mm). Differential Leukocyte Count (DLC): The neutrophil count in group I and II reduced gradually during the course of therapy when compared with the $1^{\text {st }}$ week value. In group I, the neutrophil count on $3^{\text {rd }}$ and $4^{\text {th }}$ weeks reduced non- significantly from the base line value and in group II, the neutrophil count on $2^{\text {nd }}, 3^{\text {rd }}$, and $4^{\text {th }}$ weeks decreased non-significantly from the base value. In group III, the neutrophil count decreased significantly $(\mathrm{P}<0.05)$ on $2^{\text {nd }}$ weeks after surgery and then changed non-significantly and remained within the normal range (60-75\%). In contrast, lymphocyte count showed non significant variations in groups I and II showed gradual increase at every week of therapy especially in group II. The lymphocyte count at $3^{\text {rd }}$ and $4^{\text {th }}$ week of group II varied significantly from their respective first week value. In group III, lymphocyte count increased significantly $(\mathrm{P}<0.05)$ on $2^{\text {nd }}$ week after surgery and then non significant increase and then remained within the normal range (15$30 \%$ ). However, the values of monocyte, eosinophil and basophil in the animals of all three groups remained within the normal range (monocyte 1-8\%, eosinophil 2-8\%, basophil 0-1\%).

\section{Biochemical assessment}

Alanine transaminase (ALT) levels in the animals of group I, significantly $(\mathrm{P}<0.05)$ increased during $2^{\text {nd }}, 3^{\text {rd }}$, and $4^{\text {th }}$ week of chemotherapy when compared with base value. In group II, ALT value showed non significant increase during $2^{\text {nd }}$ and $3^{\text {rd }}$ week of oncolytic gene therapy. In group III, the ALT level increased significantly $(\mathrm{P}<0.05)$ during $3^{\text {rd }}$ and $4^{\text {th }}$ week after surgery from the base line value but remained within the normal range $(8-60 \mathrm{U} / \mathrm{L})$.

Asparate transaminase (AST) level in group I showed significant $(\mathrm{P}<0.05)$ increase during $2^{\text {nd }}, 3^{\text {rd }}$, and $4^{\text {th }}$ week of chemotherapy. In group II animals, the AST values non-significantly changed during the course of oncolytic gene therapy. In group III, the AST values showed non significant increase after surgery, however, the variations were within the normal limit.

Alkaline phosphatase (ALP) increased significantly $(\mathrm{P}<0.05)$ in $2^{\text {nd }}$, $3^{\text {rd }}$ and $4^{\text {th }}$ week of therapy in group I. In group II, non significant increase in ALP levels up to $4^{\text {th }}$ weeks, while in group III, there was significant increase $(\mathrm{P}<0.05)$ in $3^{\text {rd }}$ week of therapy as compared to base values. However, the ALP values of all the three groups during course of therapy remained within the normal range (10.6-101 U/L).

\section{Flow cytometry assessment on tumour apoptosis}

In group I and group II, tumour biopsy samples were collected before and after therapy and apoptosis study was performed. In group I, highly significant $(\mathrm{P}<0.01)$ increase in apoptosis percentage was recorded at succeeding weeks of chemotherapy. In group II, there was non significant increase in apoptosis percentage after first dose of oncolytic gene construct followed by highly significant $(\mathrm{P}<0.01)$ increase in apoptosis after second and third dose of gene therapy (Figure 6A, B). The apoptosis percentage showed significant $(\mathrm{P}<0.05)$ increase in group I compared to group II (Table 3).

\section{Expression of $M M P-2$}

Estimation of Matrix metalloproteinases-2 (MMP-2) was done in the serum of mammary tumour affected canines. The sera samples collected from mammary tumour affected dogs were compared with before and after chemotherapy and gene construct therapy by ELISA. There was significant $(\mathrm{P}<0.01)$ decrease in MMP-2 activity in chemotherapy (group I) as well as in surgical therapy (group III). However, there was no significant difference in activity of MMP-2 in the serum samples of animal treated with oncolytic gene construct, indicating that the therapy doesn't have much significant effect on MMP-2 (Table 4).

\section{Discussion}

Cancer develops through a multistep process in which normal healthy cells go through stages that eventually change them to abnormal cells that multiply out of control. Tumours of mammary gland are the second most common tumours of female dog representing approximately $30-50 \%$ of all tumours, constitute an important problem in veterinary medicine ${ }^{[3,18-21]}$. Several efforts have been made towards the adoption of criteria to standardize the diagnosis, understanding tumour behavior and progression and the evaluation of prognostic factors including morphology, oncogene expression and gene alterations ${ }^{[22]}$. The knowledge and adoption of these criteria are fundamental for the selection and success of therapies that could prevent neoplasm recurrence and increase survival[ ${ }^{[1]}$.

The incidence of mammary tumours increases after the 5th year of age with a peak at the age of 10-12 years and subsequently decreases. Dogs were most often affected at the age of 10 years $^{[8,23]}$. The prevalence of mammary gland tumours in female dogs has been associated with age and breed ${ }^{[3]}$. Benign tumours were found at the age of 8-9 years. The highest relative risks of malignant tumours were reported in 13 year old $\operatorname{dogs}^{[3,8,22]}$. Our observations also confirmed this report. Increased incidence of mammary tumours was found in many large and as well as smaller breeds of dogs. Incidences of mammary tumours were found higher in pure breed dogs as compared to mongrels. Even though, non significant, there was also a higher relative risk of mammary tumours in pure breed dogs in our study. Caudal abdominal and inguinal mammary glands showed higher frequency of mammary neoplasm than thoracic glands. Posterior glands have greater volume of glandular tissue to react any carcinogenic stimulus ${ }^{[3,4]}$. 
A

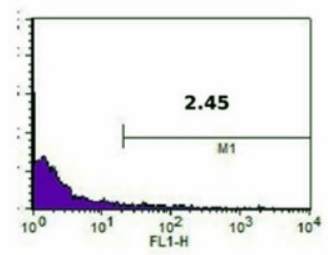

Before chemotherapy

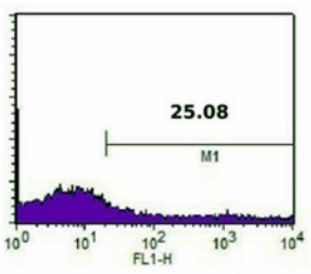

After $2^{\text {nd }}$ dose of chemotherapy

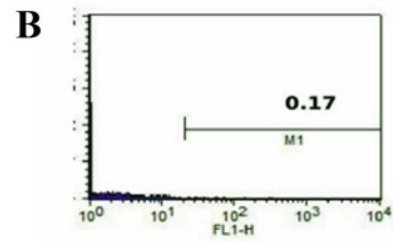

Normal canine mammary tissue

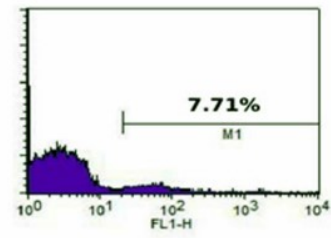

After $1^{\text {at }}$ dose of gene construct therapy

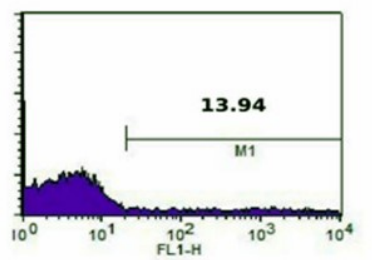

After $3^{\text {rd }}$ dose of gene construct therapy

Figure 6: Histogram plot of flow cytometry analysis showed percent apoptotic cell (MI) in CMT cases after staining with Annexin V. A: In chemotherapy group (I), B: In oncolytic gene construct therapy group (II)

Radiographs of the thorax helped to provide information pertaining to the extent of organ involved and presence of metastasis in the lung. To determine the precise clinical staging of the cancer, chest radiographs in three views (ventro dorsal, right lateral and left lateral) must be performed. The lung is the most common site for distant metastasis in dogs with malignant mammary gland tumours ${ }^{[1]}$. However, in this study, lung metastasis was observed only in one case.

Clinical staging (TNM) of the mammary tumour was carried out as per WHO classifications. Out of 30 cases recorded, 16 cases in clinical stage I $(53.3 \%)$, followed by 5 cases in clinical stage III
(16.67\%), 7 cases were in clinical stage IV (23.3\%), 2 case in clinical stage V $(6.67 \%)$ and none of the cases were seen in stage II. Similar pattern of clinical staging was also reported by Dileepkumar and coworkers ${ }^{[21]}$ in 40 clinical cases of spontaneous canine mammary tumours. Clinical staging defines the extension of neoplasms and thus established prognosis and treatment to be planned ${ }^{[1]}$. Based on this system, size of the primary lesion (T), extent of its spread to regional lymph nodes $(\mathrm{N})$ and presence or absence of distant metastasis (M) was assessed.

The histological classification has become a valuable tool for predicting biological behavior of mammary gland tumours. Therefore, it is essential to conduct histopathological examination of all nodules regardless of their size, as this provides important additional information that assists the clinician to define the prognosis and best treatment plan ${ }^{[1]}$. In veterinary medicine, the grading systems for mammary neoplasm with well-defined criteria are not frequently used ${ }^{[1]}$. The most popular histopathological classification system is based on the cellular and nuclear characteristics ${ }^{[24]}$. Mammary gland tumours arise primarily in the female animal from secretory epithelial, myoepithelial or less frequently mesenchymal elements of mammary tissue ${ }^{[25]}$. Nearly $41 \%$ to $53 \%$ of the mammary gland tumours that occur in the female dogs are malignant ${ }^{[8]}$. In this study, histopathological examination revealed similar results that about $83.3 \%$ of cases are of malignant nature and $16.67 \%$ are of benign nature. Malignant tumours histopathologically characterized by solid sheaths of neoplastic cells arranged in the form of islands with small amount of stroma and large number of mitotic figures. Similar histopathological observations were also reported by Dileepkumar and co-workers ${ }^{[21]}$, where they reported $84 \%$ of mammary gland tumours were malignant and $16 \%$ neoplasm was benign in nature.

Chemotherapy is recommended if there is histological or radiographic evidence of metastasis. In this study, treatment was done according to the nature, type, location, clinical stage and biological behavior of the tumour. Studies with the use of nanosomal paclitaxel in canine mammary tumour cases were very sparse. Hence, in the present study, use of paclitaxel has been studied and eight cases $(80 \%)$ responded well after three doses of paclitaxel and the tumour showed regression without any prominent side effects. However, two cases could not be assessed further to $2^{\text {nd }}$ dose as one case did not turn up and for the other case surgery was performed as per owner's request, though there was partial regression in tumour size. Chemotherapy has become a major treatment modality in veterinary oncology ${ }^{[26,27]}$. Taxanes are mitotic inhibitors isolated from the bark of Taxus brevifolia (Northwest Pacific Yew Tree) and named as Taxol. It was first commercially developed by BristolMyers Squibb Company with the generic name paclitaxel and sold under the trademark Taxol ${ }^{[9]}$. Paclitaxel treated cells have difficulty with the spindle assembly, cell division and also chromosome segregation. Chemotherapeutic nanoparticles provide an advantage over free drugs as they achieve slower clearance and accuracy in target delivery ${ }^{[28]}$. Nanosomes, also called liposomes, are microscopic vesicles composed of a phospholipids bilayer that are capable of encapsulating the active drug. In the present study, there was significant $(\mathrm{P}<0.01)$ increase in apoptosis percentage after treatment with nanosomal Paclitaxel showed the efficacy of this therapy.

In this study, animals of group II were treated with pVivo2.NS1.VP3 (a) $100 \mu \mathrm{g}$ per animal by intra-tumoral route. Therapy was repeated thrice at weekly interval. In two cases, there was slight infection at the sight of injection, which was treated successfully by antibiotic medicaments. Out of 10 cases, 6 cases $(60 \%)$ responded very well after three doses of gene construct therapy and the tumour showed regression. No observable side effects were reported in these cases. 
Table 3. Mean \pm SE of apoptosis (\%) recorded in dogs with mammary tumours

\begin{tabular}{cccccc} 
Group & Type of therapy & $\begin{array}{c}\text { Before } \\
\text { therapy }\end{array}$ & After $\mathbf{1}^{\text {st }}$ dose & After $\mathbf{2}^{\text {nd }}$ dose & After $\mathbf{3}^{\text {rd }}$ dose \\
\hline I & Chemotherapy & $2.20 \pm 0.16$ & $14.41 \pm 0.58^{* *}$ & $24.20 \pm 0.53^{* *}$ & $29.27 \pm 0.23^{* *}$ \\
\hline II & $\begin{array}{l}\text { Oncolytic viral } \\
\text { gene construct } \\
\text { therapy }\end{array}$ & $6.37 \pm 0.47$ & $7.46 \pm 0.13$ & $12.47 \pm 0.22^{* *}$ & $13.21 \pm 0.40^{* *}$ \\
\hline
\end{tabular}

** Mean value differ significantly at $\mathrm{P}<0.01$ within the group

Table 4. Mean \pm SE of MMP-2 estimated by ELISA in dogs with mammary tumours

\begin{tabular}{clcc} 
& Group & Before Therapy & After Therapy \\
\hline I & Chemotherapy & $3.1846 \pm .58056^{\mathrm{a}}$ & $0.5667 \pm 0.02963^{\mathrm{a}^{*}}$ \\
\hline II & $\begin{array}{l}\text { Oncolytic gene } \\
\text { construct therapy }\end{array}$ & $2.9635 \pm .48193^{\mathrm{a}}$ & $2.4093 \pm .29020^{\mathrm{b}}$ \\
\hline III & Surgical therapy & $8.2321 \pm .67737^{\mathrm{b}}$ & $5.8605 \pm .65023^{\mathrm{c}^{* *}}$
\end{tabular}

* Mean value differ significantly at $\mathrm{P}<0.05$ within the group; ** Mean value differ significantly at $\mathrm{P}<0.01$ within the group; Different superscript indicate mean value differs significantly at $\mathrm{P}<0.05$ between groups.

Two cases could not be followed up because the case did not report to the polyclinic while in other two cases, the owners sought for surgical excision of tumourous growth even though there was regression in tumour size. In this study, there was significant increase in apoptosis percentage after oncolytic gene therapy. An oncolytic virus (OV) is a virus used to treat cancer due to its ability to specifically infect and lyse cancer cells, while ideally leaving normal cells unharmed ${ }^{[29]}$. In this study a bicistronic gene construct was used, i.e NS1gene of CPV and VP3 gene of CIAV were used to explore their oncolytic ability to kill cancer cells. Among oncolytic viruses used in cancer gene therapy clinical trial, adeno and vaccinia viruses are double-stranded DNA viruses that are easy to manipulate but, have high immunogenecity. HSV are more readily used in brain tumours due to their affinity to neuron cells ${ }^{[30]}$. The NDV and reoviruses are RNA viruses which have intrinsic tumour selectivity ${ }^{[30]}$. Autonomous parvo viruses have the ability to kill transformed cells preferentially. It has been shown to suppress tumours without any adverse reactions in various animal tumour models. Parvo viruses are small $(25-30 \mathrm{~nm})$, non -enveloped viruses that multiply in cell nucleus and contain a linear, single stranded DNA consisting of two large open reading frames and smaller or overlapping genes, encoding for two non structural (NS1 and NS2) and two structural (VP1 and VP2) proteins ${ }^{[31]}$. The nonstructural proteins of parvo viruses can cause epigenetic modifications in cancer cells and transform them to a benign phenotype. Thus, antitumour efficacy by these viruses may involve both oncolysis and tumour suppression/reversion. The oncolytic effect of the autonomous rodent parvo virus $\mathrm{H}-1$ in a mouse model of mammary cancer, when given either intravenous or when mixed with the tumour cells, did not cause tissue damage and its replication in non-transformed cells was considerably attenuated, providing an important safety aspect ${ }^{[32]}$.

Chicken anemia virus (CAV), a member of the Circoviridae family, is a small non-enveloped virus containing a single-stranded circular DNA genome of $2.3 \mathrm{~kb}$. The VP3 protein of CAV, also named apoptin, which is made up of 121 amino acids has been reported to induce apoptosis in hemocytoblasts, thymocytes and lymphoblastoid cells and thus causes immunosuppression ${ }^{[33]}$. Apoptin not only induces apoptosis in chicken cells, but is also known to induce apoptosis specifically in a broad range of human transformed or tumour cells while leaving normal cells unharmed ${ }^{[34]}$. However, the molecular mechanism underlying the apoptic process induced by apoptin is not well understood ${ }^{[35]}$ and its elucidation is necessary for effective utilization of apoptin as an anti-cancer agent. Similar results were observed in a study conducted for the treatment of canine transmissible venereal tumour using canine parvo virus nslgene and chicken anemia vp3 gene. In that study animal showed signs of mild to moderate tumor regression which included features such as tumor contraction, blackening, ulceration, and a decrease in tumor size were observed, revealing the incomplete oncolytic activity of ns1 and vp3 genes. Not any untoward effects of oncolytic gene therapy were recorded in this study and revealed that in all cases, including those where complete regression did not occur, initiation of oncolytic gene therapy arrested the further progression of the tumor ${ }^{[36]}$.

In this study, apoptosis caused by viral gene construct in canine mammary tumours was moderate and lower compared to apoptosis percentage caused by nanosomal paclitaxel chemotherapy. However, if we would have included more cases in each group with similar histological type and taken one more group on gene therapy control and have considered more evaluation parameters like immunohistochemistry of tumour biopsy samples, gelatin zymography of MMP enzymes then the results as well as conclusion of this study would have been more accurate.

The entire mammary tumour cases operated surgically in group III showed uneventful recovery with no postoperative complications observed up to $18^{\text {th }}$ day except in two cases, where swelling and purulent exudation at the surgical site was observed on $4^{\text {th }}$ and $6^{\text {th }}$ postoperative day. Complete wound healing was observed in these animals on $18^{\text {th }}$ postoperative day. Tumour recurrence was not observed in any of the surgically treated animals. Surgical therapy is usually considered the routine therapy for mammary tumours with no evidence of any metastasis ${ }^{[8,21]}$.

Different clinico-physiological parameters (rectal temperature, pulse rate and respiratory rate), haematological parameters (haemoglobin, total leukocyte count and differential leukocyte count) and biochemical parameters alanine transaminase (ALT), asparate transaminase (AST) and alkaline phosphatase (ALP) are recorded in all the animals of three groups at different intervals. The results of this study showed that rectal temperature, pulse rate, respiratory rate, hemoglobin and TLC values fluctuated at different intervals in different groups; however, these changes always remained within the normal range. The neutrophil count decreased in all the three groups 
reaching the normal values which implies to improvement in the health status of animal. There was an increase in the lymphocyte count which may due to concomitant decrease in neutrophil count. Aspartate transaminase (AST) is a reliable but less specific than ALT for hepatocellular injury and necrosis ${ }^{[37]}$. AST has cytosolic and mitochondrial forms and is present in tissues of the liver, heart, skeletal muscle, kidneys, brain, pancreas, lungs, in white and red blood cells ${ }^{[37]}$. It may be due to cytotoxic. Elevation of AST in treatment of advanced breast cancer with chemotherapeutic agent epirubicin is reported. This was similar to the significant increase in AST in group I in this study. In surgical group elevation in AST can be due to muscle damage ${ }^{[37]}$. ALT is thought to be more specific for hepatic injury because it is present mainly in the cytosol of the liver and in low concentrations elsewhere ${ }^{[37]}$. The increase in ALT in groups treated with chemotherapeutic agent in this study might be due to liver damage caused by cytotoxic drugs ${ }^{[38]}$. In animals, increases in serum ALP activity are most commonly associated with hepato biliary or bone changes ${ }^{[39]}$. Similar clinico-physiological and hematobiochemical changes were also reported by other workers in the management of canine mammary tumours ${ }^{[8,21]}$.

Flow cytometry, the well established and rapid means of measuring tumour apoptosis had been applied in the present study to monitor the outcome of chemotherapy with nanosomal paclitaxel and oncolytic gene construct therapy. Programmed cell death, also known as apoptosis plays an important role in the determination of tumour growth and its aggressiveness ${ }^{[40]}$. Apoptosis plays a vital role in oncogenesis and can be used as a prognostic marker in canine mammary neoplasms ${ }^{[41]}$. Apoptosis is characterized by DNA fragmentation and chromatin condensation which differs from necrosis, later is characterized by ruptured cell membrane and swollen nuclei ${ }^{[42]}$. The study of apoptosis induced by neoplastic cells was widely used in clinical medicine against lung cancer, gastric cancer, colorectal cancer, mammary cancer and provides reliable evidences ${ }^{[22}$, 43]. In this study, apoptosis study was found very useful parameters for confirmation of effectiveness of chemotherapeutic agent nanosomal paclitaxel and oncolytic viral gene construct therapy for the management of canine mammary neoplasms.

The degradation of the extracellular matrix (ECM) and vascular angiogenesis are key factors for the growth and progression of tumours ${ }^{[44,45]}$. The activities of MMPs were significantly higher in malignant tissues than benign canine tumours ${ }^{[46]}$. In the present study the MMP-2 activity was high in mammary tumour affected dog serum which subsequently showed significant decline in activity after three doses of chemotherapy, denoting that therapy lead to decline in MMP-2 Activity.

\section{Conclusion}

The result of this study indicated that the nanosomal paclitaxel and oncolytic viral gene construct induced apoptosis in canine mammary neoplasms. However, chemotherapeutic agent (nanosomal paclitaxel) induced highly significant $(\mathrm{P}<0.05)$ percentage of apoptosis. There were no prominent side effects observed either in chemotherapy or in gene therapy. Nanosomal paclitaxel proved a promising chemotherapeutic agent in the management of canine mammary cancer. Further exploration of oncolytic viral gene construct was emphasized, to develop a novel therapeutic approach for treating canine mammary neoplasm.

\section{References}

1. Cassali GD, Lavalle GE, De Nardi AB. Consensus for the diagnosis, prognosis and treatment of canine mammary tumors. Brazilian J Vet Pathol 2011; 4(2): 153-180

2. Brodey RS, Gold Schmidt M H, Roszel JR. Canine mammary gland neoplasm. J Am Anim Hosp Assoc 1983; 19 (1): 61-66.

3. Khimta S, Maiti SK, Kumar N, Sharma AK. Occurrence of neoplasms in canine - a retrospective study. Indian J Anim. Sci 2010; 80 (1):7-11.

4. Maiti SK, Dileepkumar KM, Sandeep K, Ninu AR, Mathew D, Sangeetha P. Mammary gland tumours in male dogs: a hormonal and tumour marker study. Veterinarski Arhiv 2014; 84 (5): 537 48

5. Misdrop W. Canine mammary tumours: protective effect of late ovariectomy and stimulating effect of progestins. Vet Q 1998; 10 (1):26-33.

6. Fowler EH, Wilson GP, Koestner A. Biologic behavior of canine mammary neoplasms based on a histogenic classification. Vet Pathol 1974; 11 (3): 212-29.

7. Henderson JC and Cancellos GP. Cancers of the breast the past decade .New England J Med 1980; 302 (1):78-90.

8. Maiti SK, Manikandan M, Shivakumar U, Kumar N, Saikumar G, Gupta OP. Therapeutic evaluation of methotrexate with or without cox-2 inhibitor in the management of canine mammary tumours. Indian J Canine Pract 2011; 3 (2):117-26.

9. Priyadarshini K, Aparajitha KU. Paclitaxel against cancer: A Short Review. Med Chem. 2012; 2 (7):139-42.

10. Ghobrial IM, Thomas EW, Alex AA. Targeting apoptosis in cancer therapy. CA Cancer J Clinic 2005; 55 (3): 178-94.

11. Nelson NJ. Scientific interest in Newcastle disease virus is reviving. J Natl Cancer Inst 1999; 91(20):1708-10.

12. Phuangsab A, Lorence RM, Reichard KW, Peeples ME, Walter RJ. Newcastle disease virus therapy of human tumour xenografts: antitumor effects of local or systemic administration. Cancer Lett 2001; 172 (1): 27-36.

13. Garbett EA, Reed MWR, Brown NJ. Proteolysis in human breast and colorectal cancer. British J Cancer 1999; 81 (2):287-93.

14. Rohn JL, Zhang YH, Aalbers RI, Otto N, Den Hertog J, Henriquez NV, Van De Velde CJ, Kuppen PJ, Mumberg D, Donner P, Noteborn MH. A tumor-specific kinase activity regulates the viral death protein Apoptin. J Bio Chem 2002; 277 (52): 50820-27.

15. Rommelaere J, Geletneky K, Angelova AL, Daeffler L, Dinsart C, Kiprianova I, Schlrhofer JR, Raykov Z. Oncolytic parvoviruses as cancer therapeutics. Cytokine Growth Factor Rev 2010; 21 (2-3): $185-95$

16. Duffy MJ, Mc Carthy K. Matrix metalloproteinases in cancer: prognostic markers and targets for therapy. Intl J Oncol 1998; 12 (6): $1343-48$.

17. Sahoo S, Kataria M, Maiti SK. Isolation and characterization of stromelysin -3(MMP-11) like protein from a case of mammary carcinoma in a dog. Indian J Anim Res 2015; 49 (1):127-31.

18. Yamagami T, Kobayashi T, Takahashi, Sugiyama M. Prognosis for canine malignant mammary tumours based on TNM and histologic classification. J Vet Med Sci 1996; 58 (11):1079-83.

19. Maiti SK. Canine mammary cancer- A review. J Can Dev Res 2004; 4 (1): 65-74

20. Maiti SK, Khimta S, Bhadane B, Kumar N, Sharma AK. Therapeutic Evaluation of Herbal "Immuplus" with or without Doxorubicin in the Management of Canine Mammary Tumours. J Apply Anim Res 2009; 36 (1): 103-8.

21. Dileepkumar KM, Maiti SK, Kumar N, Zama M M S. Therapeutic Evaluation of Anti-Angiogenic and Chemotherapy with or without Cox-2 Inhibitor and Immunomodulator Drug in the Management of Canine Mammary Neoplasm. Pak Vet J 2015; 35 (3):365-70

22. Soremno K. Canine mammary gland tumours. Vet Clin North Am Small Anim Pract 2003; 33 (3): 573-96.

23. Divya M, Maiti SK, Sangeetha P, Remya V, Kumar N, Bhatia N Canine mammary tumours: An hospital based epidemiological study. India J Vet Med 2015; 35 (1) 158-62. 
24. Misdorp W, Else RW, Hellmem E, Lipscomb E. Definitions and explanatory notes .WHO classification of mammary tumours of the dog and cat .Washington: Armed forces Institute of Pathology $1999 ; 18-27$

25. Srivastava AK, Sharma AK, Singh B. Canine mammary tumours: A study on occurrence and distribution pattern. Indian J Vet Pathol 2009; 33 (1): 109-11.

26. Misdorp W. Tumors of the mammary gland. In: Meuten DJ (ed.): Tumours in Domestic Animals. 4th edn. Iowa State Press, Iowa. 2002;575-606

27. Rosenthal RC. Chemotherapy In: Veterinary Oncology (Eds).Withrow,S.J and Mac Ewen E.G.J.P. Lippincot Company, Philadelphia; 1989 pp.63-78.

28. Park S, Kang S, Chen X, Kim EJ, Kim J. Tumor suppression via Paclitaxel drug carriers that target inflammation marker upregulated in tumor vasculature and macrophages. Biomaterials. 2012; 34 (2): 598-605

29. Guo ZS, Thorne SH, Bartlett DL. Oncolytic viro therapy: Molecular targets in tumor-selective replication and carrier cellmediated delivery of oncolytic viruses. Biochim. Biophys Acta 2008; 1785 (2): 217-231.

30. Yu W, Fang H. Clinical trials with oncolytic adenovirus in China. Curr Cancer Drug Targets 2007; 7(2): 141-48.

31. Decaro N, Buonavoglia C. Canine parvovirus - a review of epidemiological and diagnostic aspects, with emphasis on type 2c. Vet Microbiol 2012; 155 (1): 1-12.

32. Bauder B, Suchy A, Gabler C, Weissenbock H. Infectious Diseases and Veterinary Public Health. J Vet Med 2001; 47 (10): 775-84.

33. McNulty. Chicken anaemia agent: a review. Avian Pathol 1991; 20 (2): $187-203$

34. Danen-Van Oorschot AA, Zhang YH, Leliveld SR, Rohn JL, Seelen MC, Bolk MW, Van Zon A, Erkeland SJ, Abrahams JP, Mumberg D, Noteborn MH. Importance of nuclear localization of apoptin for tumor-specific induction of apoptosis. J Biol Chem 2003; 278 (30): 27729-36.

35. Chen K, Luo Z, Tang J, Zheng SJ. A critical role of heat shock cognate protein 70 in Apoptin-induced phosphorylation of Akt. Biochem Biophys Res Commun 2011; 409(2): 200-04.
36. Bhat AH, Ganguly B, Tiwari AK, Das AK. Canine Parvovirus ns1 gene and Chicken Anemia vp3 gene induce partial oncolysis of Canine Transmissible Venereal Tumor. Scientific reports 2017; $7(1): 15419$.

37. Giboney TP. Mildly Elevated Liver Transaminase Levels in the Asymptomatic Patient American Family Physician 2005; 71 (6): 1105-10.

38. Bain PJ. Liver. In Duncan and Prasse's Veterinary Laboratory Medicine: Clinical Pathology. Iowa State University Press, Ames. IA; 2003 pp 193-214.

39. Daniela E, Dana W, Frances C, David L. Effects of Hepatic Drugmetabolizing Enzyme Induction on Clinical Pathology Parameters in Animals and Man. Toxicol Pathol 2010; 38 (5):810-28.

40. Gonzáles-cámpora R, Galera- Ruiz MR, Vázquez- Ramírez $\mathrm{F}$, Ríos- Martín JJ, Fernández -Santos JM, Ramos- Martos MM, Gomez-Pascual A. Apoptosis in Breast carcinoma. Pathol Res Pract 2000; 196 (3): 167-74.

41. Pereira PD, Lopes CC, Matos AJF, Santos M, Gartner F, Medeiros R, Lopes C. COX-2 Expression in Canine Normal and Neoplastic Mammary Gland. J Comp Path 2009; 140 (4): 247-53

42. Nagata S, Goldstein P. The Fast death factor. Science 1995; 267 (5203): 1449-56.

43. Yu-wen $\mathrm{C}, \mathrm{Xu} \mathrm{W}$, Chun-feng J, Li-hong Z, Ying H, Hong-dang $\mathrm{H}$. A study of tumor apoptosis induced by medicine serum of traditional Chinese medicine. J US-China Med Sci.2007; 4 (1):5155.

44. Stetler-Stevenson WG. Dynamics of matrix turnover during pathologic remodeling of the extracellular matrix. Amer. J. Pathol.1996; 148 (5): 1345-50.

45. Kawai K, Uetsuka K, Doi K, Nakayama H. The activity of matrix metalloproteinases (MMPs) and tissue inhibitors of metalloproteinases (TIMPs) in mammary tumors of dogs and rats. J Vet Med Sci 2006; 68 (2):105-11.

46. Nakaichi M, Yunuki T, Okuda M, Une S,Taura Y. Activity of matrix metalloproteinase-2 (MMP-2) in canine oronasal tumors. Res Vet Sci 2007; 82 (2):271-79.

\author{
Abbreviations \\ AST : Aspartate Transaminase \\ ALT : Alanine Transaminase \\ ALP : Alkaline Phosphatase \\ CIAV : Chicken infectious anemia virus \\ CMN : Canine mammary neoplasm \\ CPV : Canine parvo virus \\ DLC : Differential leukocyte count \\ DNA : Deoxyribo nucleic acid \\ ECM : Extra cellular matrix \\ ELISA : Enzyme linked immunosorbant assay \\ FACS : Fluorescence Activated Cell Sorter \\ HSV : Herpes simplex virus \\ MMPs : Matrix metalloproteinases \\ NDV : Newcastle disease virus \\ NS1 : Non structural protein 1 \\ NS2 : Non-structural protein 2 \\ OV : Oncolytic virus \\ RNA : Ribo nucleic acid \\ TNM : Tumour, lymph node, metastasis \\ VP : Viral capsid protein \\ WHO : World Health Organization
}




\section{Potential Conflicts of Interests}

There are no conflicts of interest to report.

\section{Acknowledgments}

The authors are highly thankful to Director, ICAR-Indian Veterinary Research Institute (IVRI), Izatnagar 243 122, Uttar-Pradesh, India for providing necessary facilities to carry out the present work and Dr K P Singh, Principal Scientist, CADRAD, IVRI for assisting histopathological works of this study.

\section{Corresponding Author}

Swapan Kumar Maiti, Principal Scientist, Surgery Division, ICAR-Indian Veterinary Research Institute, Izatnagar-243 122, Uttar-Pradesh, India; Email: swapanivri@gmail.com; maiti_62@rediffmail.com 